\title{
LA HUELLA DEL RETABLO DE SAN BENITO DE ALONSO BERRUGUETE EN EL OBISPADO DE PALENCIA
}

\author{
THE INFLUENCE OF ALONSO BERRUGUETE'S \\ SAN BENITO ALTARPIERCE IN PALENCIA'S BISHOPRIC
}

\author{
Jesús María Parrado del Olmo \\ Universidad de Valladolid. España \\ parrado@fyl.uva.es
}

\begin{abstract}
El retablo de San Benito plantea diversas novedades en la composición arquitectónica, que dejaron una huella importante en el panorama de la escultura palentina del segundo cuarto del siglo XVI.

Palabras clave: retablo; Alonso Berruguete; Francisco Giralte; Juan Ortiz el Viejo I; Juan de Valmaseda.
\end{abstract}

San Benito's altarpierce presents certain architectural novelties that influenced in Palentinian sculpture in the second quarter of the $16^{\text {th }}$ century.

Keywords: altarpierce; Alonso Berruguete; Francisco Giralte; Juan Ortiz el Viejo I; Juan de Valmaseda.

Durante la primera mitad del siglo XVI el retablo castellano se basa en propuestas arquitectónicas diseñadas por Felipe Bigarny y Alonso Berruguete. El primero domina el panorama del diseño de retablos hasta su muerte en 1542, y en especial debió tener un papel preponderante en la orientación retablística a partir de que en el año 1514 el rey Fernando el Católico le nombrara "hacedor y examinador de todas las obras de talla que se hicieren de aquí adelante en los reinos de Castilla". Como indica Isabel del Río, el cargo le debió deparar una situación preeminente a la hora de contratar retablos e imponer sus criterios a otros maestros ${ }^{1}$.

${ }^{1}$ RÍO DE LA HOZ, Isabel: El escultor Felipe Bigarny (h. 1470-1542). Salamanca, 2001, pp. 117-118. 
Pero en relación con la originalidad de las trazas, Alonso Berruguete planteó novedades importantes en el diseño con la intención de considerar el retablo como una fachada organizada de una manera solemne. He dedicado un trabajo al estudio del mismo en Alonso Berruguete y sus posibles fuentes ${ }^{2}$. Si en el retablo del monasterio jerónimo de la Mejorada de Olmedo (Museo Nacional de Escultura de Valladolid), el orden principal se estructura con columnas clásicas, en el del monasterio de San Benito de Valladolid, Berruguete introduce el balaustre, lo que no va a abandonar a lo largo de su producción. Este retablo va a tener trascendencia en el medio palentino del segundo cuarto de siglo en varias obras, que vamos a estudiar a continuación.

El retablo del monasterio de San Benito de Valladolid supuso una revolución en el concepto de la retablística española del siglo XVI. Su organización arquitectónica supuso una gran novedad, pues a partir de las propuestas platerescas creadas probablemente en torno a Felipe Bigarny, Alonso Berruguete supo utilizar los recursos arquitectónicos aprendidos en Italia para crear una obra monumental, de gran poder envolvente hacia el espectador a quien estaba destinada su contemplación, y al mismo tiempo novedosa en sus planteamientos. La gran máquina diseñada por el maestro fue desmontada sin ningún rigor, tras la Desamortización de 1835 , y en la iglesia quedaron algunas piezas del ensamblaje ${ }^{3}$.

Manuel Arias ha estudiado las claves iconográficas del retablo en función de las necesidades religiosas de la orden benedictina, considerando que su traza estaba pensada para poder explayar mejor las ideas en torno a la realidad mesiánica que se pretendía comunicar a los monjes. Al mismo tiempo, ha propuesto una reconstrucción bastante plausible del mismo, auxiliándose de la puesta en vigor de nuevos elementos arquitectónicos y ornamentales existentes hasta ese momento en los almacenes del Museo de Nacional de Escultura, los cuales ahora se exponen al público tras la restauración del edificio y de sus piezas, a partir de un dibujo diseñado por Villar Bueno ${ }^{4}$. De esta manera, la nueva propuesta añade elementos peculiares a la realizada en su tiempo por Candeira ${ }^{5}$.

2 PARRADO DEL OLMO, Jesús María: "El retablo del Renacimiento y los Jerónimos. La Mejorada de Olmedo y El Parral de Segovia", Boletín del Seminario de Estudios de Arte y Arqueología, LXVI, 2000, pp. 199-216.

${ }^{3}$ BOSARTE, Isidoro: Viage artístico a varios pueblos de España... T. I. Madrid, 1804, pp. 359-376; y CANDEIRA, Constantino: Alonso Berruguete en el retablo de San Benito el Real de Valladolid. Valladolid, 1963, p. 40.

${ }^{4}$ VILLAR BUENO, C.: "Intervención en el retablo de San Benito en el Museo Nacional de Escultura de Valladolid”, Museos.es, 0, 2004, pp. 80-89; y ARIAS MARTÍNEZ, Manuel: "Las claves iconográficas del retablo de San Benito el Real, de Alonso Berruguete", Boletín del Museo Nacional de Escultura, 9, 2005, pp. 13-27.

${ }^{5}$ CANDEIRA, C.: Alonso Berruguete..., op. cit., p. 40. 
El retablo de San Benito fue una novedad revolucionaria en las trazas de los grandes retablos. En el mismo, Berruguete se decanta decididamente por el balaustre y abandona el orden clásico utilizado en el gran cuerpo del retablo del monasterio de la Mejorada de Olmedo (Museo Nacional de Escultura de Valladolid). Las dos grandes novedades aportadas por este retablo fueron su disposición tripartita, con una exedra en la parte central de la máquina y dos alas rematadas en frontones, y la idea de recoger los dos grandes cuerpos de que consta la obra por medio de columnas que agrupan dos subcuerpos. Distintas fuentes de la arquitectura antigua y de la altorrenacentista se funden en esta sorprendente obra ${ }^{6}$. En todo caso, la arquitectura de este retablo renuncia a la disposición en un plano, característica del retablo de Bigarny y busca el movimiento en planta.

También tuvo gran originalidad el uso del orden gigante para unificar cada uno de los grandes cuerpos del retablo, a su vez divididos en dos subcuerpos. A diferencia del orden lateral propuesto por Bigarny, en Berruguete las columnas unifican toda la anchura de la estructura, creando una arquitectura en forma de pórtico. Ya hemos anticipado que usó aquí el balaustre como orden columnario, puesto en boga en Castilla por Felipe Bigarny, desde que aparece por primera vez en el retablo mayor de la capilla Real de Granada. Berruguete se acomoda así al gusto artístico impuesto en Castilla y desecha la modernidad del orden clásico. También es posible que considerara que el retablo era una estructura formada por una arquitectura más decorativa que estructural, y como tal, la columna abalaustrada, por su mayor ligereza y versatilidad ornamental podía ser más apropiada. Aplicado de la manera que hizo en el retablo de San Benito, el orden utilizado salvaba la altura considerable del mismo con un tipo de órdenes que fijaban una organización unitaria en cada uno de los dos grandes cuerpos, y al tiempo creaba una arquitectura solemne y grandiosa, lo que, unido a la disposición movida de la planta, indica la huella que la arquitectura romana y la altorrenacentista había dejado en Berruguete. El mismo sistema lo volverá emplear en el retablo del Colegio de Irlandeses de Salamanca, máquina plana por necesidad de adaptarse al espacio dispuesto en el muro de cierre original de la capilla, contratado en 1529. Al ampliarse la capilla en 1549, el retablo sufrió cierta ampliación ${ }^{7}$.

Un retablo del medio palentino que toma pronto ideas extraídas del retablo de San Benito es el de la capilla del Sagrario de la catedral de Palencia (Figura 1). Atribuido por Weise al Maestro del Sagrario, según un nombre genérico diseñado por él, Portela ha situado el retablo en la órbita de los escultores Juan Ortiz

${ }^{6}$ PARRADO DEL OLMO, J. M.: "El Retablo del Renacimiento...”, op. cit., pp. 199216; y ARIAS MARTÍNEZ, Manuel: Alonso Berruguete, Prometeo de la escultura. Palencia, 2011, pp. 97-116.

7 SENDÍN CALABUIG, Manuel: El Colegio Mayor del Arzobispo Fonseca en Salamanca. Salamanca, 1977, pp. 127-172; y ARIAS MARTÍNEZ, M.: Alonso Berruguete..., op. cit., pp. 121-130. 
el Viejo I y Juan de Valmaseda, aunque no está documentado ${ }^{8}$. Sin embargo en este caso, se puede saber la fecha de su construcción, a través de lo que indican las actas de la catedral. La capilla, que en principio iba a ser el tramo del fondo de la capilla mayor, presenta una bóveda de crucería de finales del siglo XV, que deja un espacio de poca altura ${ }^{9}$. Aquí hubo un retablo costeado por doña Inés de Osorio $(† 1492)$-dama noble que dejó un importante legado a la obra de la catedral-, cuyas imágenes estaban guarnecidas de plata. En 1529 se decidió sustituir el retablo por otro nuevo, aprovechando el valor de la plata del mismo, no sin reticencias por parte del canónigo Salazar, quien prefería conservarlo por razón "de su antigüedad" ". En agosto de 1529 se manda deshacer toda la obra, a excepción de la Virgen con el Niño. El retablo se haría entre esta fecha y la de 1534, cuando se contrata su policromado por Andrés de Espinosa y Cristóbal de Herrera ${ }^{11}$.

Por lo tanto, el retablo se debió iniciar antes de que estuviera terminado el retablo de San Benito, que fue tasado en 1532. Ello no fue óbice para que éste dejara una profunda huella en la traza del retablo palentino, lo que nos indica que las ideas de un taller del siglo XVI se extendían pronto. En este caso quizá el influjo pudo llegar a través de algún colaborador palentino de Alonso Berruguete en aquel retablo vallisoletano, uno de los muchos que pudieron ayudar al maestro en una obra tan compleja ${ }^{12}$.

8 WEISE, Georg: Spanische Plastik aus sieben Jahrhunderten. T. III, II. Reutlingen, 1925-1932, p. 218. Bajo este nombre genérico, el hispanista alemán agrupó un conjunto de obras del obispado de Palencia, influidas por Felipe Bigarny, que pueden identificarse con el estilo de Juan Ortiz, si bien a partir de este retablo del Sagrario, también entran componentes siloescos que, por su estilo dramático, serían introducidos por Juan de Valmaseda. Ver PORTELA SANDOVAL, Francisco J.: La Escultura del Renacimiento en Palencia. Palencia, 1977, pp. 82-113, especialmente pp. 82-86. PARRADO DEL OLMO, Jesús María: "Precisiones sobre escultura palentina del siglo XVI. Nuevas atribuciones al taller vigarnista-siloesco", en Actas del I Congreso de Historia de Palencia. T. I. Palencia, 1987, pp. 147-159.

9 MARTÍNEZ GONZÁLEZ, Rafael: La arquitectura gótica en la ciudad de Palencia (1165-1516). Palencia, 1989, p. 131.

10 VIELVA RAMOS, Matías: Monografía acerca de la Catedral de Palencia. Palencia, 1923, pp. 55-56; GARCÍA CUESTA, Timoteo: "La Catedral de Palencia según los protocolos", Boletín del Seminario de Arte y Arqueología, XX, 1954, p. 63; ARA GIL, Clementina Julia: "La actividad artística en la catedral de Palencia durante los obispados de Diego Hurtado de Mendoza y Fray Alonso de Burgos (1471-1499)", en Jornadas sobre la Catedral de Palencia. Valladolid, 1989, pp. 87-88; y PARRADO DEL OLMO, Jesús María: "Evolución artística de la catedral de Palencia a través del gobierno de los obispos del Renacimiento", en Jornadas sobre la Catedral de Palencia, op. cit., pp. 148-149.

${ }^{11}$ GARCÍA CUESTA, T.: "La catedral...", op. cit., pp. 67-69.

${ }^{12}$ El influjo del orden del retablo de San Benito llega muy pronto, hacia 1535, al retablo de la iglesia de Ventrosa (La Rioja), obra de Pierres de París y Diego Ruiz. Ver 
El retablo de la capilla del Sagrario se adapta a un espacio mucho más reducido que la monumental capilla mayor del monasterio de San Benito, por lo que la traza del modelo original sufre una reducción evidente. Sobre un alto banco, es el único retablo que presenta una exedra central, cuya forma cóncava se prolonga en el ático, dispuesto para albergar el Calvario, aunque se desecha el cierre avenerado del modelo vallisoletano y se prefiere una caja central para el crucifijo y dos planos curvos para la Virgen y San Juan. Remata en un medio punto de progenie bigarnista, con un busto femenino en su interior. Las dos alas que integran las calles laterales unifican sus dos cuerpos a través de columnas abalaustradas que unifican los cuerpos, las cuales son de canon grueso, al modo habitual en otros retablos palentinos en torno a Juan de Valmaseda. Sin embargo en la exedra, se prefiere coger cada cuerpo con un orden propio, que es de fuste tallado a candelieri en el cuerpo bajo y abalaustrado en el superior. Las alas laterales no rematan en frontones como en el retablo de Alonso Berruguete, pero se insinúa una forma triangular en la disposición de los dos elementos avolutados que cobijan un ángel cantor. El tipo de veneras planas de las cajas para los relieves es similar a los empleados por Bigarny en Granada. La decoración ya presenta grutescos, en especial en las pilastras del banco.

La novedad que supuso este retablo tan evolucionado en el medio de la propia catedral queda subrayada, si se compara con la traza muy tradicional, de casillero, con pilastras y sencillas decoraciones a candelieri, aún derivada del retablo mayor de la seo palentina, que muestra el retablo de la capilla de San Gregorio, en el que también trabaja el escultor Juan Ortiz el Viejo $\mathrm{I}^{13}$. Esta obra se hizo a partir de 1528, cuando se concede la capilla al canónigo don Juan de Arce, sobrino de fray Alonso de Burgos, y se le exige que haga reja, retablo y vidriera; es decir, en fechas muy cercanas al retablo del Sagrario ${ }^{14}$.

Pero como se ha indicado repetidamente por la crítica, el retablo que sigue más directamente al retablo de San Benito es el de San Pedro de Cisneros, obra de Francisco Giralte, que he situado en torno a 1542, aunque otros lo sitúan, infundadamente a mi parecer, hacia 1535 (Figura 2). En esta obra se sigue de cerca la subdivisión en dos grandes cuerpos, cogidos por un solo sistema de columnas abalaustradas, el retranqueo de la zona central, aunque sustituyendo la exedra por tres paños, y los frontones con soldados durmientes dispuestos de espaldas ${ }^{15}$.

RUIZ-NAVARRO PÉREZ, Julián: "La Escultura del Renacimiento y Manierismo en La Rioja”, en Historia del Arte en La Rioja. El siglo XVI. Logroño, 2007, p. 206.

${ }_{13}$ PORTELA SANDOVAL, F. J.: La escultura..., op. cit., pp. 94 y ss.

${ }^{14}$ SAN MARTÍN PAYO, Jesús: "Catálogo del Archivo de la Catedral de Palencia", Publicaciones de la Institución Tello Téllez de Meneses, 50, 1983, pp. 304-305; y PARRADO DEL OLMO, J. M.: "Evolución artística...", op. cit., pp. 149-151.

${ }^{15}$ Entre la copiosa bibliografía de este retablo, se puede destacar MARTÍ Y MONSÓ, José: Estudios Histórico-artísticos relativos principalmente a Valladolid. Valladolid-Madrid, 
Sin duda es el retablo palentino que sigue más de cerca el modelo de Alonso Berruguete, lo que se explica por la constancia del trabajo de Giralte en el taller berruguetesco. La presencia de un influjo directo de la sillería del coro de la catedral de Toledo -en la que también trabajó Giralte- en el Josué y en el David de este retablo, aconsejan situar su fecha de ejecución, a partir de la realización de la obra toledana, entre 1539 y 1542.

En la década de 1540-1550 los talleres palentinos abordaron la ejecución de grandes retablos mayores como los de Torremormojón, San Cebrián de Campos o San Pedro de Becerril de Campos -hoy en la iglesia del Sagrario de Málaga-. No están documentados y se adscriben a la colaboración entre Juan Ortiz el Viejo I y Juan de Valmaseda, si bien es probable que colaboren otros anónimos escultores y entalladores. El primero, muy relacionado en elementos arquitectónicos, decoración y estilo de la escultura con el segundo tiene una organización convencional pues cada uno de sus cuerpos lleva su propio orden. Los otros dos son más interesantes desde el punto de vista de lo que nos ocupa.

El monumental retablo de la iglesia parroquial de San Cornelio y San Cipriano de San Cebrián de Campos presenta un alto banco, cuatro cuerpos unidos de dos en dos y ático (Figura 3). En la vertical tiene tres calles y cuatro entrecalles, las extremas en ligero saliente como en Torremormojón, al modo bigarnista. La calle central es plana por lo que se desecha la exedra empleada en el retablo de la capilla del Sagrario de la catedral palentina o los paños del retablo de Cisneros. Sin embargo, este retablo sigue de cerca al retablo del monasterio de San Benito por la subdivisión en la horizontal en dos grandes cuerpos, como se acusa en la mayor anchura de los entablamentos, apoyados cada uno de ellos por un solo orden de seis columnas abalaustradas. Las mismas presentan el grueso fuste que hemos visto en la capilla del Sagrario. Es posible que sea el retablo de Cisneros el modelo en el que se basa éste de San Cebrián de Campos.

Se establece así una organización monumental que deriva del retablo vallisoletano de Berruguete, aunque sin el complejo movimiento de éste, pues aquí se busca una sencilla adaptación a la planta poligonal de la capilla mayor del templo. En el ático, las formas mixtilíneas entre candeleros que cierran las calles laterales, que cobijan relieves de San Juan Bautista y la Magdalena, fingen cintas o filacterias colgantes. Sobre la caja del Calvario hay otro remate mixtilíneo. Todo esto resulta arcaico, puesto que ya se empleaban en retablos palentinos de finales de la década de 1520 y 1530 . Esto nos indica la persistencia de fórmulas de gusto artístico en los medios locales. Sin embargo, el remate en forma de frontón estilizado situado sobre las entrecalles extremas puede admitirse como una reducción de los grandes frontones que cierran las alas laterales del retablo de San Benito.

1898-1901, pp. 327-342; CANDEIRA, C.: Alonso Berruguete..., op. cit., p. 40; PORTELA SANDOVAL, F. J.: La escultura..., op. cit., p. 263; y PARRADO DEL OLMO, J. M.: Los escultores..., op. cit., pp.137-141. 
La decoración con cabezas de serafines de los grandes frisos sigue la iniciada por Bigarny. Pero en los frisos secundarios y en el banco aparece una decoración más avanzada con temas mitológicos como Hércules y el centauro Neso, mascarones, templetes, armas, colgantes de frutas y paños colgantes o "draperies", que son ya de progenie manierista.

El retablo se ha datado en torno a 1540-1548 y se ha puesto en relación con Juan de Valmaseda ${ }^{16}$. Por mi parte, también aprecio la mano del taller de Juan Ortiz el Viejo I en algunas esculturas y relieves del retablo. También se ha insinuado la participación del entallador Juan de Cambray, y se han hecho subgrupos estilísticos en la escultura. Habría que plantearse si no podría estar interviniendo en estos retablos palentinos de la década de los años cuarenta el enigmático Luis Ortiz, hijo de Ortiz el Viejo, del que no se conserva ninguna obra documentada, por lo que no se puede saber cuál era su orientación estética ${ }^{17}$.

En otros retablos aparece una mayor libertad en el uso del orden unificador, sin utilizarlo de un modo secuencial a lo largo del mismo cuerpo, sino escalonándolo en los distintos pisos. El antecedente será el retablo de San Ginés de Villabrágima de Francisco Giralte. El retablo de San Pedro de Becerril de Campos, que fue trasladado en 1943 a la capilla del Sagrario de la catedral de Málaga (Figura 4), se ha puesto en relación con el taller de Juan de Valmaseda, aunque Camón Aznar indicaba que había un estilo en la escultura de ritmos enardecidos, de manera que Portela admitía fuertes influjos berruguetescos, con ecos de Francisco Giralte, y planteaba también la posibilidad de intervención de Juan de Cambray ${ }^{18}$. Por mi parte, he visto estilos muy diferentes, como ecos propios del estilo avanzado de Juan Ortiz el Viejo I, de Juan de Valmaseda -o quizá de Miguel de Espinosa-, y otros berruguetescos, interpretados de un modo elegante, relacionables con la primera etapa de Manuel Álvarez y su círculo ${ }^{19}$. Recientemente se ha publicado un dibujo de la colección Abelló, en el que se muestra la mitad de una traza que coincide en lo esencial con la de este retablo ${ }^{20}$. El retablo debe datarse a fines de la década de 1540-1550, si bien indica Portela que no se terminaría hasta 1565. En 1568 contrataban su policromía Floristán Pérez y Cristóbal de

16 WEISE, G.: Spanische plastik..., op. cit., tomo III, II, p. 218; CAMÓN AZNAR, José: "Juan de Balmaseda", Goya, 12, 1956, p. 364; y PORTELA SANDOVAL, F. J.: La escultura..., op. cit., pp. 159-162.

${ }^{17}$ Los subgrupos estilísticos en CABALLERO, Arturo: San Cebrián de Campos. Iglesia de los Santos Cornelio y Cipriano. Palencia, 1994, pp. 30-38. Sobre Luis Ortiz ver PARRADO DEL OLMO, J. M.: Los escultores seguidores..., op. cit., pp. 323-326.

18 WEISE, G.: Spanische plastik..., op. cit., tomo III, II, pp. 234-235; CAMÓN AZNAR, J.: "Juan de Balmaseda", op. cit., p. 368; y PORTELA SANDOVAL, F. J.: La escultura ..., op. cit., pp. 164-166.

19 PARRADO DEL OLMO, J. M.: Los escultores..., op. cit., pp. 94-97, 212-213 y 293.

${ }^{20}$ URREA, Jesús: “¿Una traza para el retablo mayor del Sagrario de Málaga?”, Boletín de la Real Academia de la Purísima Concepción de Valladolid, 47, 2012, pp. 35-38. 
Herrera $^{21}$. Pero se debió hacer a partir de 1584 por Simón de Cisneros y Gómez de Ugea $^{22}$. Las relaciones del tipo de columnas y de su decoración con las del púlpito de la iglesia de Aranda de Duero (Burgos), contratado en 1547 por Juan de Cambray y Miguel de Espinosa, indican una fecha en torno a la cual se pudo iniciar éste.

El retablo presenta banco, tres cuerpos y ático muy desarrollado. Presenta tres calles y cuatro entrecalles. En la iglesia de Becerril adoptaba un quiebro de las zonas laterales para adaptarse a los paños de la capilla mayor, mientras que en la del Sagrario de Málaga se le ha dispuesto de forma plana ${ }^{23}$.

La traza es un dibujo elaborado, que no es un simple rasguño sino que está diseñado con cierta precisión, lo que indica que su autor es un buen maestro. Así se advierte que busca el detalle en algunos elementos como la decoración manierista del pedestal del banco, el orden gigante situado encima o el diseño de uno de los frisos. De igual manera trabaja la perspectiva de la arquitectura y el claroscuro para darle relieve. Las figuras representadas también son rasguños hechos con precisión sintética, tanto en la disposición de las movidas composiciones de los cuerpos, como la definición de los ropajes y del volumen a través del sombreado. Todas presentan un canon alargado y muestran un evidente influjo berruguetesco, alejado del estilo de Juan Ortiz el Viejo I y de Juan de Valmaseda.

La traza ofrece variantes con respecto a la ejecución final tanto en lo estructural como en lo iconográfico. En el primer caso, las columnas diseñadas son gruesos balaustres y en su ejecución final son muy finos y estilizados, e incluso desaparecen los estrangulamientos del fuste en el último cuerpo. Solo los dos órdenes gigantes de los extremos se asemejan a los propuestos en el dibujo. También surgen cambios en la disposición de estos órdenes, que también van escalonados. Mientras la traza dispone el orden de los extremos abarcando los dos cuerpos inferiores, en el retablo está entre los cuerpos superiores. Si en aquélla se plantea un segundo orden a ambos lados de la calle central, entre los cuerpos superiores, en el retablo definitivo se situó entre el primer y segundo cuerpo, abarcando la hornacina de San Pedro y San Pablo, y gran parte de la de la Asunción, buscando así unificar los dos grupos iconográficos más significativos. El efecto de sobreelevación parece advertirse en la calle central, que incrusta un cuerpo en otro, a la manera de Juan de Juni, a su vez continuado por Giralte en el retablo de la capilla

${ }^{21}$ REDONDO AGUAYO, Anselmo: "Monografía histórica de la villa de Becerril de Campos. Noticia biográfica de sus hijos más ilustres", Publicaciones de la Institución Tello Téllez de Meneses, 9, 1953, p. 177.

${ }^{22}$ El retablo tiene la fecha de 1585 en la hornacina derecha. Ver PARRADO DEL OLMO, J. M.: Los escultores..., op. cit., p. 97, documento $\mathrm{n}^{\circ} 9$.

${ }^{23} \mathrm{Su}$ montaje en la iglesia de Becerril puede verse en una fotografía publicada por REDONDO AGUAYO, A.: "Monografía histórica...", op. cit., p. 177; y por PORTELA SANDOVAL, F. J.: La escultura..., op. cit., lám. 158. 
del Doctor Corral. También hay algunos cambios en el ático: el frontón de la caja del Calvario no lleva la crestería del dibujo y hay variantes en los aletones que la flanquean; frente al medallón ovalado con un busto, ornado por cueros recortados, se prefiere una forma mixtilínea algo arcaica para la fecha. Sí se respetaron las figuras de arcángeles en los extremos.

En cuanto a la iconografía, se respetó el tema dibujado en el banco, que además se ajusta a la composición del dibujo, aunque añadiendo más elementos. En cambio, en el primer cuerpo, lo diseñado parece ser Santiago en la batalla de Clavijo, pero se talló la conversión de San Pablo, más relacionada con la temática del retablo. En el segundo cuerpo, no hay dibujo sino una inscripción que dice: "la muerte de Nuestra Señora con los apóstoles". Sin embargo, la Dormición de la Virgen se situó en el tercer cuerpo, y en su lugar se colocó la curación del paralítico por San Pedro, también más relacionado con la advocación del retablo.

Todas estas variantes me hacen pensar que la traza dibujada, pese a estar cortada por la mitad, como es habitual para que una parte la tenga la iglesia contratante y otra el taller que ejecuta el retablo, no era la definitiva. Por el contrario, quedaban algunos aspectos iconográficos que decidir, y se estaba a la espera de la decisión final de los contratantes. Por eso, en un cuerpo solo se coloca la inscripción del tema y el tercero está vacío. Al final, se decidió la iconografía actual. Igualmente el taller, de acuerdo con los promotores o no, cambió aspectos de la arquitectura y de la decoración del ático.

Las esculturas de los apóstoles de las entrecalles no se corresponden con las dibujadas. El estilo nervioso y el canon alargado no es habitual en el medio palentino, pero en todo caso, su indudable procedencia berruguetesca y algunas relaciones con la arquitectura del retablo de San Ginés de Villabrágima pudiera indicar que se debiera a Francisco Giralte, del que no conocemos su estilo de dibujante, pese a que el maestro emplea habitualmente un canon corto. Se sabe que hizo trazas para obras realizadas por otros artistas, como indican varios testigos del pleito de la Antigua, y podríamos estar ante un caso de traza encargada al escultor para otro u otros maestros ${ }^{24}$. Otra hipótesis sería la de que en principio, pensaba participar en este retablo, pero su marcha a Madrid hizo que traspasara su participación a su cuñado, el citado Manuel Álvarez.

Relacionado con este retablo en la utilización descontextualizada de los órdenes gigantes es el mayor de la iglesia de Santa María de Boadilla del Camino. El contrato, según Portela debe datar de 1548, y fue realizado por los entalladores Juan de Cambray, Pedro de Flandes y Mateo Lancrín, lo que se documenta a través de la concordia de un pleito entablado por el cobro de una deuda de la iglesia hacia los autores en $1568^{25}$. Es un retablo con banco, tres cuerpos y ático, y tres

${ }^{24}$ MARTÍ Y MONSÓ, J.: Estudios Histórico-artísticos..., op. cit., pp. 326-353.

${ }^{25}$ GARCÍA CHICO, Esteban: Nuevos documentos para el estudio del arte en Castilla. Escultores del siglo XVI. Valladolid, 1959, pp. 134-135. Sobre el retablo ver PORTELA 
calles y dos entrecalles internas en la vertical. A la manera del retablo del Sagrario de Málaga, la colocación de los órdenes gigantes se distorsiona, puesto que aparece en forma de columna con el tercio inferior del fuste tallado y abarcando los dos cuerpos inferiores en los extremos de la calle lateral, que a su vez se corresponde con otro orden gigante abalaustrado en el interior. Sin embargo, el orden gigante se escalona a ambos lados de la calle central, pues aquí abarca los cuerpos superiores, recogiendo las cajas principales con los temas marianos.

El influjo del retablo de San Benito termina con un retablo ya más evolucionado, en el que se puede suponer un influjo serliano, como es el de Arrabal de Portillo (Valladolid) (Figura 5). En este retablo de tres cuerpos, los dos inferiores van agrupados por un solo orden de columnas jónicas, que son dobles a los extremos. La utilización de los órdenes presta un aire monumental al retablo, de tal manera que las calles laterales y entrecalles, solo separadas por finas pilastras quedan integradas dentro del tramo que marcan las columnas. En el remate vuelven a aparecer los frontones, con figuras tendidas, como en el retablo de San Benito, aunque en este caso se sustituyen los soldados por niños rollizos. La solemnidad unida a la claridad de las líneas arquitectónicas que marcan los órdenes seguramente derivan de Serlio, de quien también se toman los codillos de las cajas rectangulares del banco ${ }^{26}$.

Fecha de recepción: 4 de enero de 2017

Fecha de aceptación: 8 de febrero de 2017

SANDOVAL, F. J.: La escultura..., op. cit., pp. 199-201. El retablo tiene un tipo de columnas similares al retablo del Rosario de la iglesia de Simancas (Valladolid), realizado en 1550 y 1551. Ver MARTÍN GONZÁLEZ, J. J.: Catálogo Monumental de la Provincia de Valladolid. Antiguo Partido Judicial de Valladolid. Valladolid, 1973, p. 98; y DE LA PLAZA SANTIAGO, Francisco Javier: "El retablo de Nuestra Señora del Rosario, en Simancas", Boletín del Seminario de Estudios de Arte y Arqueología, XXXVII, 1971, pp. 295310. En este retablo, el orden gigante aparece solo a los extremos, siguiendo la disposición tradicional iniciada por Bigarny. PARRADO DEL OLMO, J. M.: Los escultores..., op. cit., pp. 80-82. Planteo la posible colaboración de distintos escultores en el retablo de Boadilla del Camino, subarrendados por los contratantes que solo eran entalladores.

${ }^{26}$ El retablo ha sido atribuido a Francisco Giralte, pero es muy probable que haya una colaboración entre maestros, uno de los cuales sería Manuel Álvarez. Ver especialmente: PORTELA SANDOVAL, F. J.: La escultura..., op. cit., pp. 197 y 269; PARRADO DEL OLMO, J. M.: Los escultores..., op. cit., pp. 100-103 y 159-161; y PARRADO DEL OLMO, J. M.: "Manuel Álvarez", en Jornadas sobre el Renacimiento en la provincia de Palencia. Palencia, 1987, p. 103. 


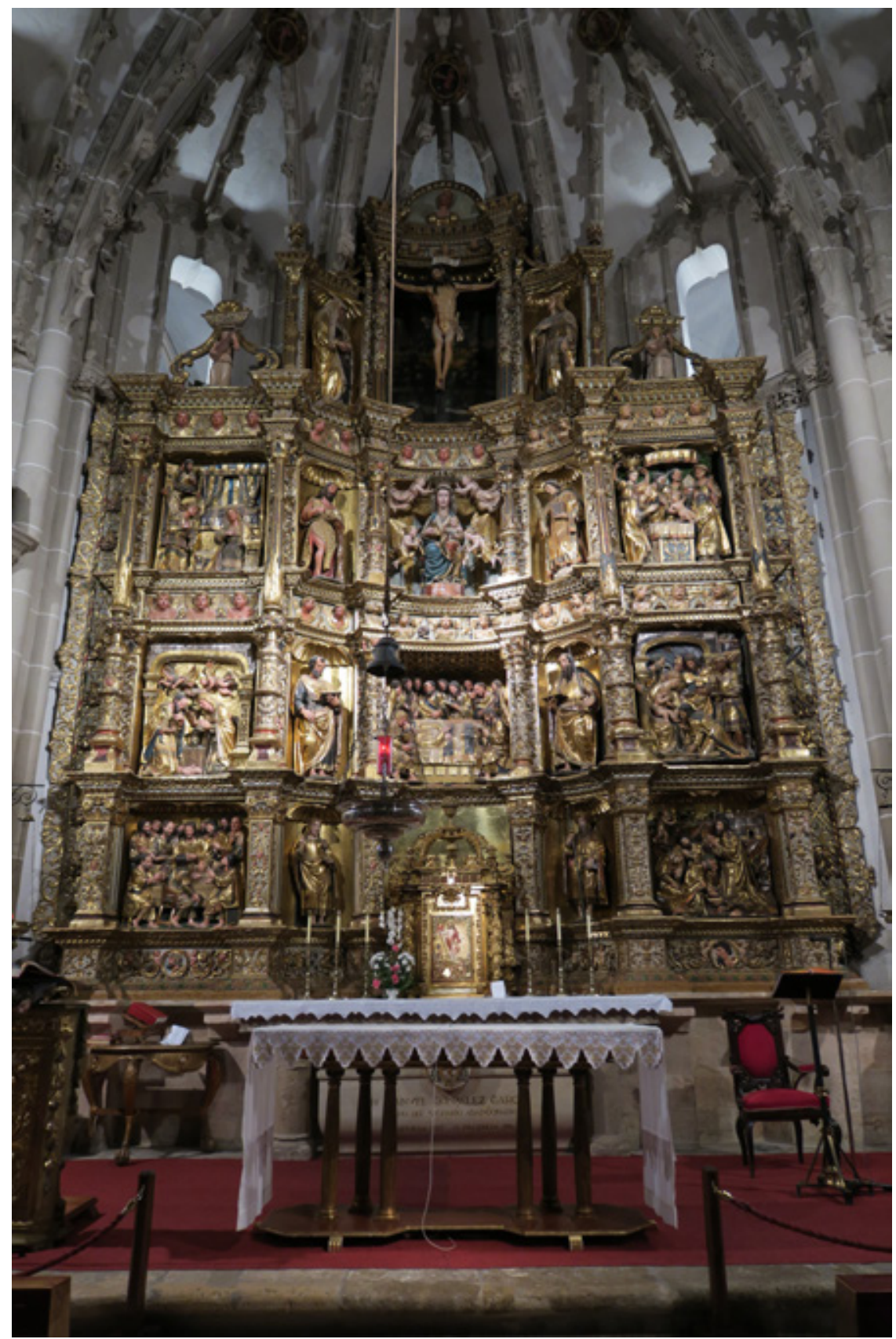

Figura 1. Retablo, capilla del Sagrario de la catedral de Palencia.

LABORATORIO DE ARTE 29 (2017), pp. 107-120, ISSN 1130-5762 e-ISSN 2253-8305 - DOI http://dx.doi.org/10.12795/LA.2017.i29.05 


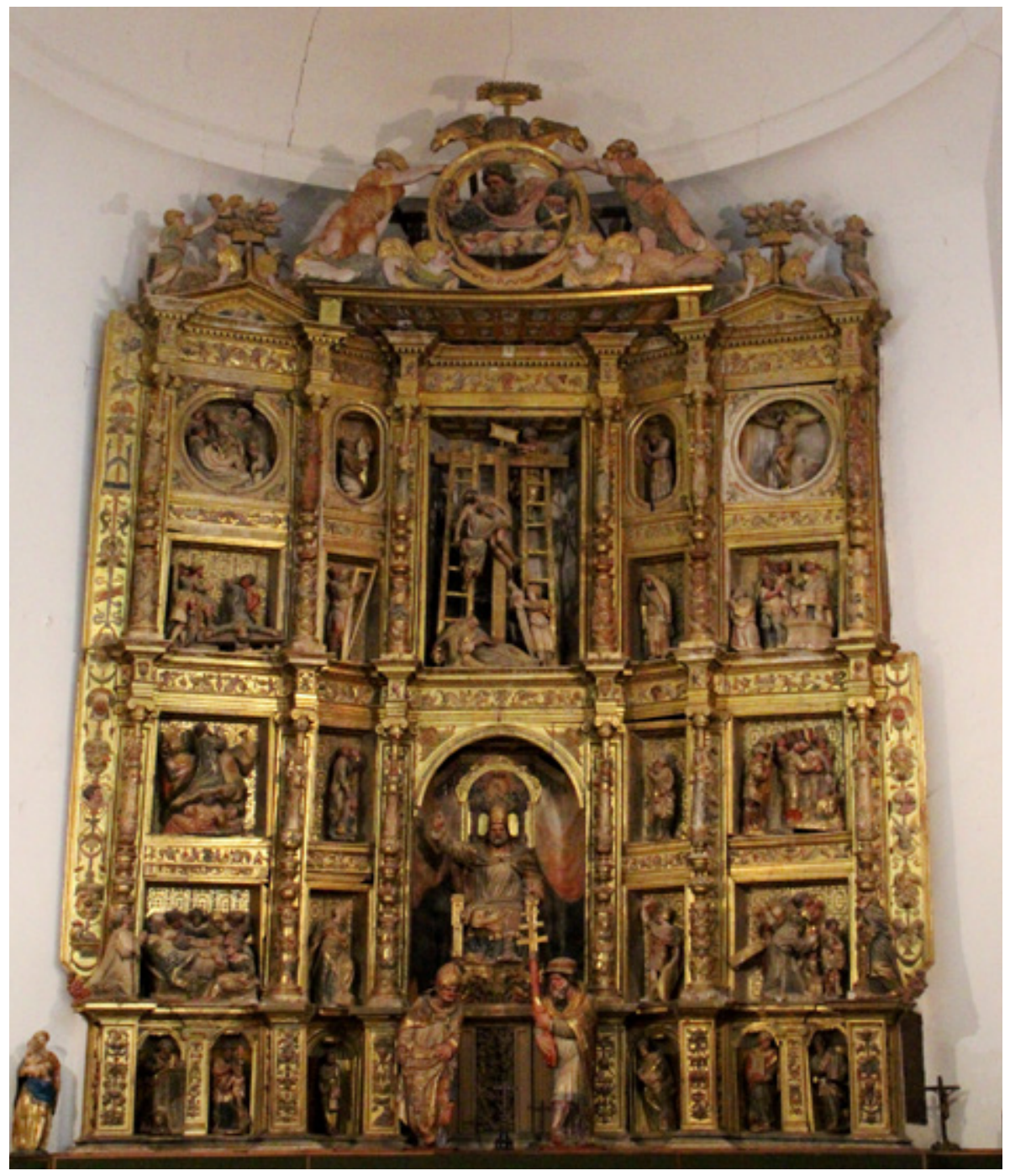

Figura 2. Retablo mayor, iglesia de San Pedro de Cisneros (Palencia). 


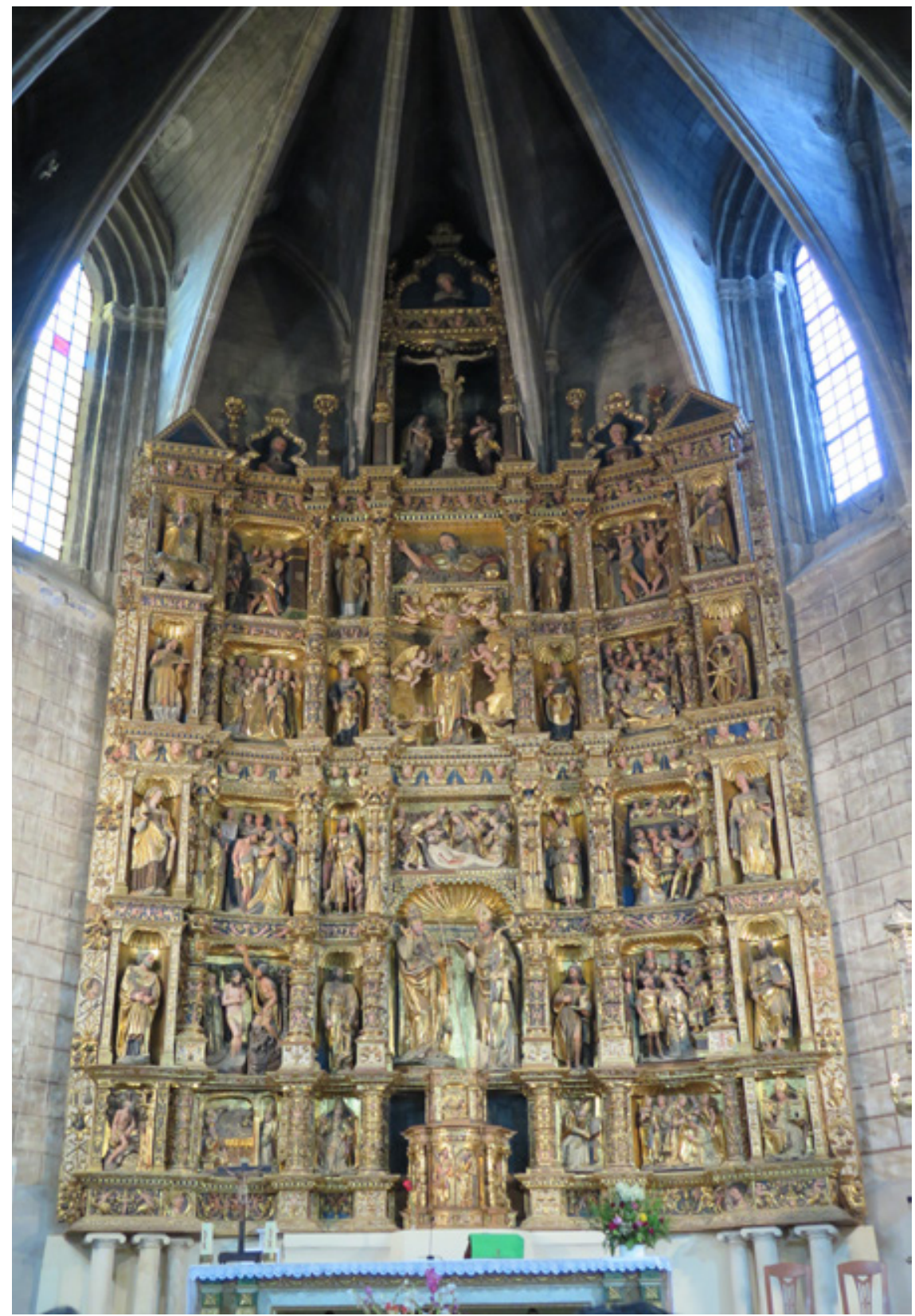

Figura 3. Retablo mayor, iglesia parroquial de San Cebrián de Campos (Palencia).

LABORATORIO DE ARTE 29 (2017), pp. 107-120, ISSN 1130-5762 e-ISSN 2253-8305 - DOI http://dx.doi.org/10.12795/LA.2017.i29.05 

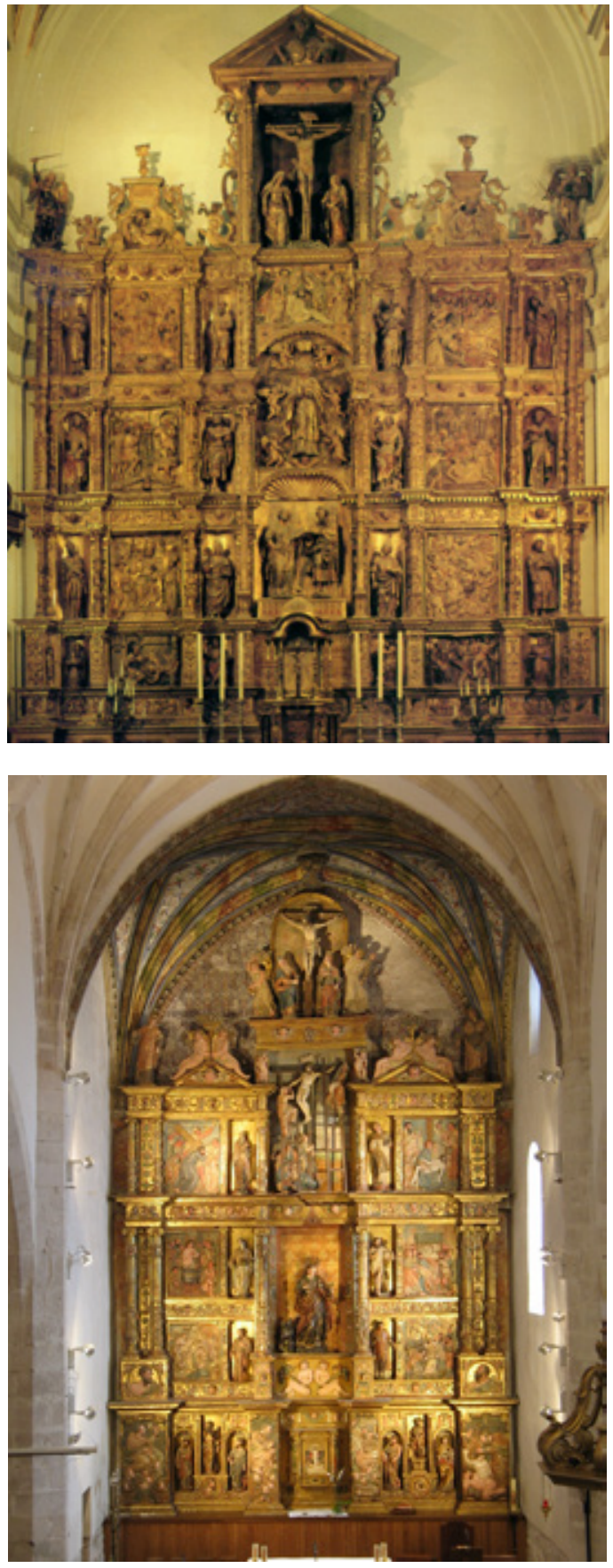

Figura 4. Retablo mayor, capilla del Sagrario de la catedral de Málaga.
Figura 5. Retablo mayor, iglesia parroquial de Arrabal de Portillo (Valladolid).

LABORATORIO DE ARTE 29 (2017), pp. 107-120, ISSN 1130-5762 e-ISSN 2253-8305 - DOI http://dx.doi.org/10.12795/LA.2017.i29.05 